\title{
Restricted cusp motion in right-left type of bicuspid aortic valves: A new risk marker for aortopathy
}

\author{
Alessandro Della Corte, MD, PhD, ${ }^{a}$ Ciro Bancone, $\mathrm{MD},{ }^{a}$ Carlo A. Conti, $\mathrm{PhD},{ }^{\mathrm{b}}$ Emiliano Votta, PhD, \\ Alberto Redaelli, PhD, ${ }^{\mathrm{b}}$ Luca Del Viscovo, $\mathrm{MD},{ }^{\mathrm{c}}$ and Maurizio Cotrufo, $\mathrm{MD}^{\mathrm{d}}$
}

\begin{abstract}
Objective: Bicuspid aortic valve disease is heterogeneous with respect to valve morphology and aortopathy risk. This study searched for early imaging predictors of aortopathy in patients with a bicuspid aortic valve with rightleft coronary cusp fusion, the most common morphotype.
\end{abstract}

\begin{abstract}
Methods: Time-resolved magnetic resonance imaging was performed in 36 subjects with nonstenotic, nonregurgitant bicuspid aortic valves and nondilated aortas and in 10 healthy controls with tricuspid aortic valves. Sinus dimensions (diameter, width, and height), ascending tract diameters, and wall strain were measured for each sinus/leaflet unit and corresponding ascending tract area to account for asymmetries. A novel parameter, "cusp opening angle," measured the degree of valve leaflet alignment to outflow axis in systole, quantifying cusp motility. Phase-contrast magnetic resonance imaging and computational fluid dynamic models assessed flow patterns. Aortic growth rate was estimated over a follow-up period ranging from 9 to 84 months.
\end{abstract}

Results: The expected restriction of bicuspid aortic valve opening (conjoint cusp opening angle, $62^{\circ} \pm 5^{\circ}$ vs $76^{\circ} \pm 3^{\circ}$ for nonfused leaflet and $75^{\circ} \pm 3^{\circ}$ for tricuspid aortic valve cusps; $P<.001$ ) was confirmed, and the introduced parameter reproducibly quantified this phenomenon. Phase-contrast magnetic resonance imaging demonstrated systolic flow deflection toward the right, affecting the right anterolateral ascending wall. Computational models confirmed that restricted cusp motion alone is sufficient to cause the observed flow pattern. Ascending tract wall strain was not circumferentially homogeneous in bicuspid aortic valves. In multivariable analyses, the conjoint cusp opening angle independently predicted ascending aorta diameters and growth rate $(P<.001)$.

Conclusions: In the bicuspid aortic valve commonly defined as normofunctional by echocardiographic criteria, restricted systolic conjoint cusp motion causes flow deflection. The novel measurement introduced can quantify restricted cusp opening, possibly assuming prognostic importance. (J Thorac Cardiovasc Surg 2012;144:360-9)

Supplemental material is available online.

The association of congenital bicuspid aortic valve (BAV) and ascending aorta dilatation is the object of controversies both pathogenetic and clinical in nature. ${ }^{1-5}$ As far as the pathogenetic question is concerned, the genetic theory,

From the Department of Cardiothoracic Sciences, ${ }^{a}$ Second University of Naples c/o Monaldi Hospital, Naples, Italy; Department of Bioengineering, ${ }^{\mathrm{b}}$ Politecnico di Milano, Milan, Italy; Department of Experimental and Clinical Internist Medicine, ${ }^{c}$ Section of Diagnostic Imaging, Second University of Naples, Naples, Italy; and Department of Cardiovascular Surgery, ${ }^{\mathrm{d}}$ Pineta Grande Hospital, Castelvolturno, Italy.

Dr Bancone was supported by the $\mathrm{PhD}$ program "Physiopathology of the Cardiorespiratory System and Associated Biotechnologies," Second University of Naples, Italy.

Disclosures: Authors have nothing to disclose with regard to commercial support.

Received for publication July 30, 2011; revisions received Sept 7, 2011; accepted for publication Oct 4, 2011; available ahead of print Nov 4, 2011.

Address for reprints: Alessandro Della Corte, MD, PhD, V. Monaldi Hospital, via L. Bianchi, 80131 Napoli, Italy (E-mail: aledellacorte@libero.it).

0022-5223/\$36.00

Copyright (c) 2012 by The American Association for Thoracic Surgery

doi: $10.1016 /$ j.jtcvs.2011.10.014 implying a still unidentified genetic defect causing arterial wall fragility, ${ }^{2}$ and the hemodynamic theory, whereby aortic wall degeneration is caused by the abnormal post-valvular flow imposing undue stress loads on the aorta, ${ }^{3}$ have been so far considered mutually exclusive. As to the clinical aspects, epidemiology, pathobiology, and surgical studies have led some authors to recommend, on the basis of purported similarities with Marfan syndrome aortopathy, more aggressive indications to aortic surgery in BAV than in patients with tricuspid aortic valve (TAV), ${ }^{2}$ whereas according to others, earlier indications may not be universally justified. $^{4}$

Conclusive resolution of these controversies is probably hindered by the heterogeneity of phenotypes falling under the definition of BAV aortopathy, ${ }^{5-7}$ hampering consistency among studies. BAV-related aortic disease can assume disparate anatomo-clinical forms, each associated with unique baseline features and valve morphology or function of a patient, as first pointed out by our previous studies ${ }^{6}$ and then confirmed by others, although with different formal classifications. ${ }^{7,8}$ Natural history can vary, as well, from early development of aneurysm to lifelong freedom from aortopathy. ${ }^{9}$ 


$$
\begin{aligned}
& \text { Abbreviations and Acronyms } \\
& \begin{aligned}
\text { BAV } & \text { bicuspid aortic valve } \\
\text { COA } & =\text { cusp opening angle } \\
\text { ICD } & =\text { intercommissural distance } \\
\text { MRI } & =\text { magnetic resonance imaging } \\
\text { STJ } & =\text { sinotubular junction } \\
\text { TAV } & =\text { tricuspid aortic valve } \\
\text { TrueFISP } & =\text { true fast imaging with steady-state } \\
& \text { precession } \\
\text { WS } & =\text { wall strain }
\end{aligned}
\end{aligned}
$$

Therefore, a third pathogenetic theory can be issued, that is, the hypothesis that clinical heterogeneity may be subtended by individually variable combinations of coexisting genetic and hemodynamic causative factors. ${ }^{5,6,10}$ Scientific attention should then be shifted from the "genetic versus hemodynamic" dilemma that might be incorrectly formulated to the need for discrimination, in the individual patient, of the respective contributions of either pathogenetic factor. Improvements in the understanding of this pathogenetic diversity and consequent prognostic variability have been advocated, because they could provide novel tools to guide individualized patient management. ${ }^{10}$

In the present study, possible aortopathy risk markers were sought by magnetic resonance imaging (MRI) in a selected BAV setting characterized by right-left coronary cusp fusion, echocardiographically normofunctional valve, and nondilated aorta.

\section{PATIENTS AND METHODS \\ Study Population}

Asymptomatic patients with a definite diagnosis of congenital BAV without aortic stenosis (peak velocity $<2 \mathrm{~m} / \mathrm{s}$ ), with no or trivial aortic regurgitation, and without dilatation of the aorta (diameter indexed to body surface area $<2.2 \mathrm{~cm} / \mathrm{m}^{2}$ ) ${ }^{11}$ were prospectively recruited among those under echocardiographic follow-up. Causes for exclusion were cardiovascular medication, previous cardiothoracic surgery, coarctation, hypertension, Marfan syndrome or other connective tissue defect, and atherosclerosis. For phenotypic homogeneity, only patients with a right-left coronary cusp fusion pattern were included. Thus, 36 patients with BAV (33 male, 3 female; mean age, $28 \pm 7$ years) underwent cardiac phase-contrast cine-MRI assessment after written informed consent. Ten healthy volunteers with TAV ( 9 male, 1 female; mean age, $33 \pm 12$ years) served as the control group. Echocardiographic follow-up of patients with BAV was continued ( 1 examination every 3 months) by blinded operators, and ascending tract diameter progression was assessed. This study was approved by the local ethics committee.

\section{Magnetic Resonance Imaging Protocol}

Both black-blood (T1-weighted) images and electrocardiogram-gated breath-hold true fast imaging with steady-state precession (TrueFISP) cine-sequences were obtained on a 1.5T MRI scanner (Siemens Magnetom Avanto, Erlangen, Germany). Typical scan parameters for TrueFISP sequences included repetition time/echo time $47 / 1.3 \mathrm{~ms}$, bandwidth 600
$\mathrm{kHz}$, field of view 280 to $320 \mathrm{~mm}$, matrix size $192 \times 192$, slice thickness $6 \mathrm{~mm}$, spatial resolution $1.5 \times 1.5 \times 6 \mathrm{~mm}^{3}$, and 25 frames/cycle.

In addition to routine cardiac chamber measurements, an original protocol of special views and measurements for the aorta was applied, including 3 double oblique slices ("long axis" with respect to the aorta; Figure 1, A). Each slice passed through the middle of 1 sinus, and the resulting views were thereby named "left coronary," "right coronary," and "noncoronary" ( 3 sinuses were always distinguished in patients with BAV).

Measurements (inner-to-inner edge) included (1) intercommissural distances (ICDs), that is, the maximal width of each sinus in diastole (Figure 1, $B)$; (2) systolic and diastolic diameters at the following levels: aortoventricular junction ("annular plane"), root (maximal bulging of the sinuses of Valsalva), sinotubular junction (STJ), and tubular tract of the ascending aorta (Figure 1,C); (3) distances between the annular plane and the other diameters (to control for consistency of measurement levels among the 3 above longitudinal views); and (4) angle of each leaflet relative to the annular plane at the time point of maximal valve opening (Figure 2). This parameter, named "cusp opening angle" (COA), was introduced to quantify the motility of a leaflet as its tendency to align to the outflow axis (defined as a line orthogonal to the annular plane) in systole. The on-screen protractor tool featured by the workstation software equipment was used for angle measurements.

Phase-contrast, time-resolved sequences were also acquired (repetition time/echo time, $61 / 3.1 \mathrm{~ms}$; velocity encoding, $150-200 \mathrm{~cm} / \mathrm{s}$ ) in both the 3 long-axis views and the short-axis views, with in-plane and through-plane velocity encoding, respectively.

Furthermore, aortic wall strain (WS), as previously defined in echocardiography studies, ${ }^{12,13}$ was calculated by the formula WS $=100$ $\left(\mathrm{AoD}_{\mathrm{s}}-\mathrm{AoD}_{\mathrm{d}}\right) /\left(\mathrm{AoD}_{\mathrm{d}}\right)$, where $\mathrm{AoD}_{\mathrm{s}}$ and $\mathrm{AoD}_{\mathrm{d}}$ are systolic and diastolic diameters at the tubular tract level, respectively. Systodiastolic changes in diameters were measured in the 3 aforementioned long-axis scan-planes to detect possible asymmetries, that is, differences in strains among the 3 radial directions explored by "right coronary," "left coronary," and "noncoronary" views (Figure E1). Time points of systole and diastole were determined on the basis of cardiac contraction and blood flow.

\section{Statistical Methods}

MRI measurements were taken in duplicate by 2 experienced operators. Reproducibility was verified in the first 8 subjects with BAV and 4 subjects with TAV for diameters, as well as in the first $22 \mathrm{BAV}$ and in all controls for COAs, by calculating the coefficient of variation (standard deviation of the differences, expressed as percentage of the mean) for both intraobserver and interobserver variabilities.

Data are presented as mean \pm standard deviations and counts (percentages) for continuous and categoric variables, respectively. Comparisons among groups were performed by Student $t$ and chi-square tests. Comparisons within groups (eg, COA in left coronary view vs COA in the other 2 views) were performed by 1 -way analysis of variance with Bonferroni correction. Correlations were tested through Pearson's linear correlation with 2-tailed significance assessment. Multivariable stepwise linear regression models were developed to find independent predictors of ascending diameters (covariates entered in the models included baseline features, as listed in Table 1, BAV/TAV status, ICDs, annulus and root diameters, sinus heights, COAs, and WS) and aortic size growth rates in the follow-up of BAV subjects (including as covariates the COAs, initial diameters, and WS values). Analysis was performed using the Statistical Package for the Social Sciences 13.0 (SPSS Inc, Chicago, Ill).

\section{Computational Fluid Dynamics}

To gain insight in the interpretation of MRI results, 2 computational fluid dynamics models were created, simulating fluid dynamics downstream of the TAV and BAV, respectively. In this study, we used computational fluid dynamics models to simulate a theoretic condition isolating the rheologic effect of different cusp anatomy and motility (BAV vs TAV) from 

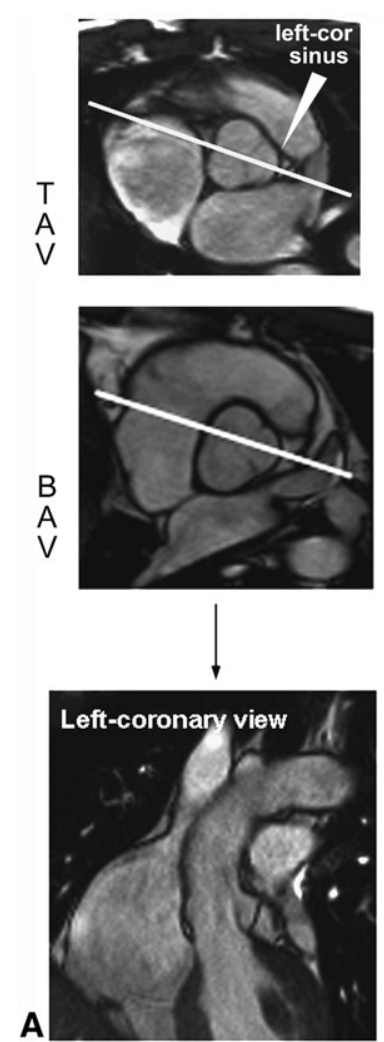
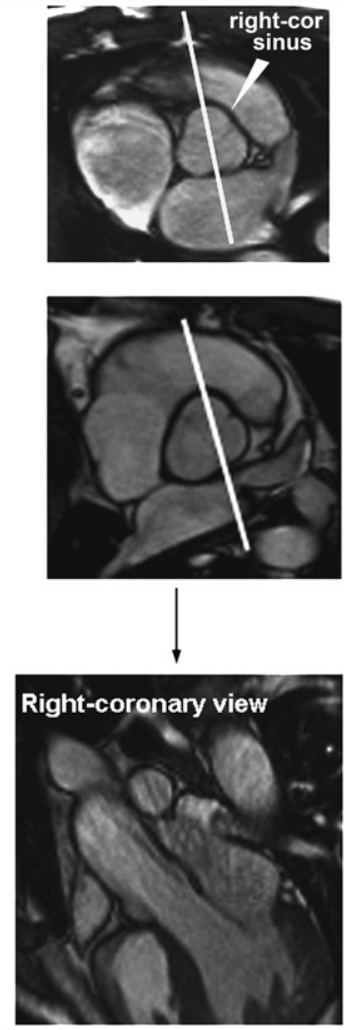
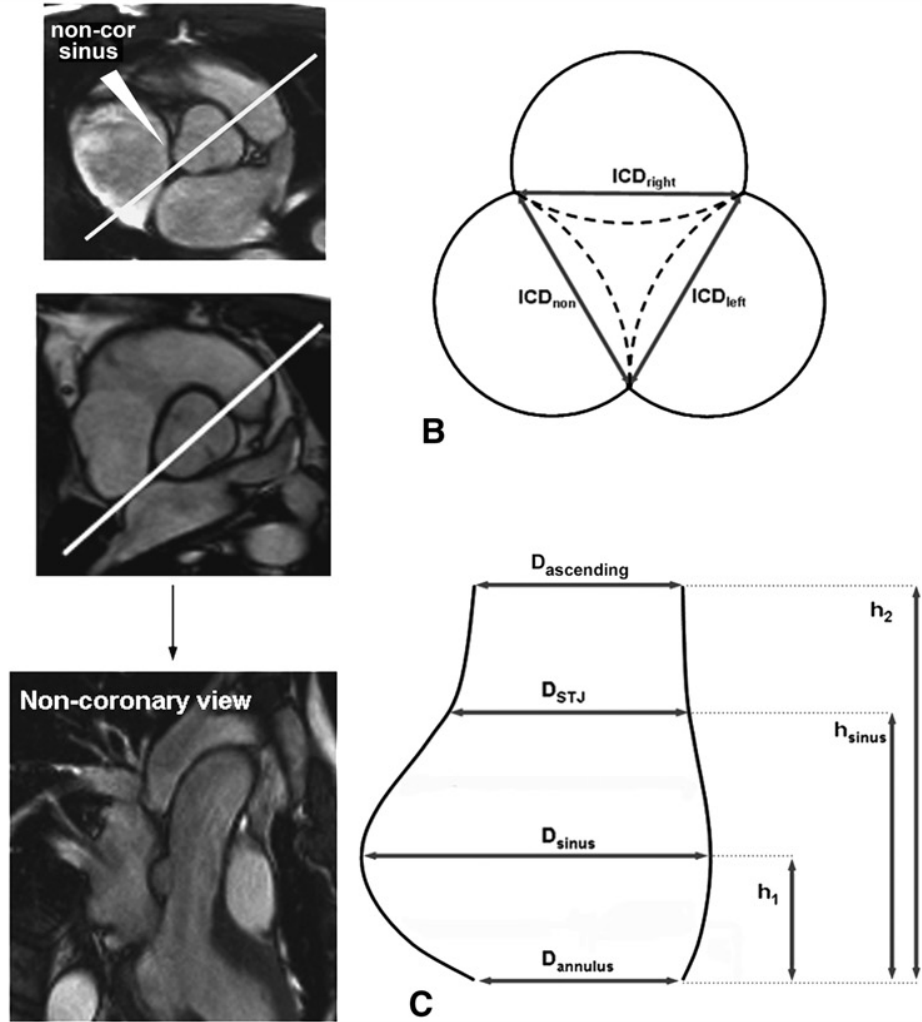

FIGURE 1. MRI measurements. A, Cross-sectional diastolic view of the TAV and BAV root (top) with prescription of 3 long-axis views (bottom), each passing through 1 commissure (or raphe) and the midpoint of the opposite sinus wall, for which the view is named. B, Diagram of sinus width measurement (ICD). C, Diagram of diameter and height measurements. $h$, Height; $D$, diameter; $I C D$, Intercommissural distance; $B A V$, bicuspid aortic valve; $T A V$, tricuspid aortic valve.

the possible effect of other factors (aortic diameters, wall elasticity), and not to attempt a depiction of the forces developing in the real setting. The quantification of flow-related wall stress went beyond the aims of the present study, and therefore no fluid-structure interaction model was implemented.

The FLUENT finite-volume software (Ansys Inc, Canonsburg, Pa) was used to solve the governing equations, that is, the 3-dimensional, unsteady incompressible continuity and Navier-Stokes equations. TAV and BAV aortic root geometry were defined according to our previously published structural models, based on MRI measurements from the first 8 patients with BAV enrolled and from all subjects with TAV. ${ }^{14,15}$ The 2 geometric models were scaled to obtain equal ascending aorta diameters, thus ruling out the possible contribution of different aortic dimensions in determining flow differences, and then completed with an aortic arch model accounting for the degree of curvature and the off-planarity shape. ${ }^{16}$ The entire intraluminal volume was then discretized into $1 \times 10^{7}$ tetrahedra to define the fluid domain. Vascular walls were assumed rigid, ${ }^{16}$ and a physiologic waveform inflow was prescribed at the proximal end of the models. Flow velocity patterns were computed and color-scale encoded to be qualitatively compared with phase-contrast MRI images, focusing on postvalvular systolic jet direction.

\section{RESULTS}

\section{Root Geometry}

Patients with BAV and patients with TAV were comparable in terms of baseline characteristics (Table 1). Although within the normal range, the mean diameter of the ascending tubular tract was significantly greater in those with BAV $(P<.001)$. The BAV root was more consistently asymmetric than the TAV root, with the noncoronary sinus showing the greatest dimensions, in terms of diameter ( $P=.14$ by analysis of variance), width, and height (Table 2). Variability for all root measurements ranged from $1.2 \%$ to $3 \%$ (intraobserver) and $1.6 \%$ to $3.3 \%$ (interobserver).

\section{Valve, Flow, and Wall Dynamics}

As shown in Table 2, COA was significantly narrower for the BAV conjoint cusp, that is, when measured in left coronary $\left(\mathrm{COA}_{\text {left }}\right)$ or right coronary view $\left(\mathrm{COA}_{\text {right }}\right.$, both $P<.001$ vs corresponding TAV leaflets), whereas noncoronary $\mathrm{COA}\left(\mathrm{COA}_{\text {non }}\right)$ was comparable. Intraoperator and interoperator variabilities were $2.4 \%$ and $3.4 \%\left(\mathrm{COA}_{\text {non }}\right)$, $3.2 \%$ and $4.0 \%\left(\mathrm{COA}_{\text {left }}\right)$, and $3.3 \%$ and $3.5 \%\left(\mathrm{COA}_{\text {right }}\right)$, respectively.

COA quantified the expected misshaped BAV opening. In short-axis cine-sequences, the orifice remained roughly elliptical and eccentric in systole, whereas TAVs showed a normal central opening, with a more regular shape (Figure 3, $A$ and $B$ ). 

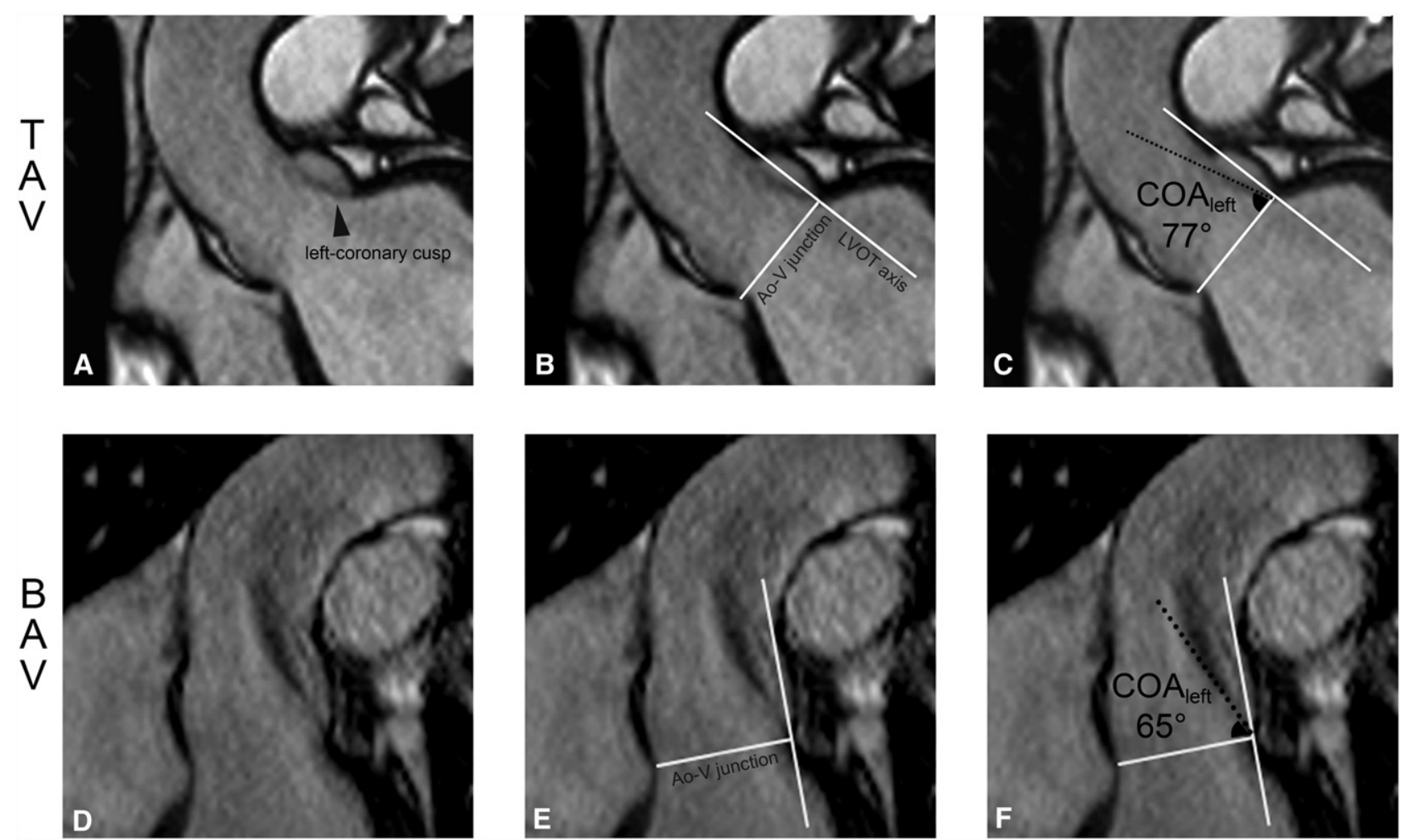

FIGURE 2. Examples of COA measurement in the "left coronary" view (A, D). The transversal plane passing through the proximal end of the root depicted the aortoventricular junction, or "annular plane" (whereas the orthogonal line represents the outflow axis; B, E). The angle between the cusp (dotted line passing in the body of the leaflet section) and the annular plane was measured (C, F). Ao-V, Aortoventricular; LVOT, left ventricular outflow tract; COA, cusp opening angle; $B A V$, bicuspid aortic valve; $T A V$, tricuspid aortic valve.

Both TrueFISP time-resolved sequences (Figure 3, $C$ and $D$ ) and phase-contrast MRI sequences (Figure $4, A$ ) showed that the flow jet downstream of the BAV was skewed toward the right in all cases; it impacted the wall area downstream of the noncoronary sinus, that is, the right anterolateral wall, in all subjects with BAV (Figure 4, A). A retrograde systolic flow component in the tubular tract was a finding unique to subjects with BAV.

Computational models, where both TAV and BAV aorta had the same diameters and wall rigidity, closely reproduced the asymmetric flow pattern found in vivo, confirming that cusp opening restriction was sufficient to cause the pattern of flow misdirection observed by MRI, irrespective of aortic size and wall properties (Figure 4, $B-D)$.

Aortic WS at the tubular tract was significantly lower in subjects with BAV than in subjects with TAV only when measured in the long-axis scan-plane passing through the noncoronary sinus (Table 2). The BAV group showed significant spatial heterogeneity of WS, with the noncoronary view displaying the lowest strain value $(7.4 \%)$. Conversely, the TAV aorta showed homogeneous WS values along the aortic circumference $(11 \%$ in all 3 views).

\section{Correlations of Cusp Opening Angle}

In the entire study cohort, both $\mathrm{COA}_{\text {left }}$ and $\mathrm{COA}_{\text {right }}$ showed significant inverse correlations with ascending diameters $(P<.001$; Figure $5, A)$, whereas correlations with sinus and STJ diameters were weaker (all $r \leq 0.4$ ). In the BAV group, $\mathrm{COA}_{\text {left }}(r=-0.47, P=.004)$ and $\mathrm{COA}_{\text {right }}$ ( $r=-0.45, P=.007)$ showed a negative correlation with age. The noncoronary ICD was strongly correlated with coronary COAs (eg, for the $\mathrm{COA}_{\text {left }}$ in BAVs, $r=-0.77$, $P<.001$ ), whereas no significant correlations were observed between COAs and other measurements (including peak velocity).

The predictors of ascending aorta dimensions emerging from multivariable linear regression models in the overall study population were $\mathrm{COA}_{\text {left }}$, sinus diameter, and body surface area $\left(\mathrm{R}^{2}\right.$ of the models range, 0.71-0.79). Of note, BAV/TAV status was not a determinant. In subjects with $\mathrm{BAV}$, the $\mathrm{COA}_{\text {left }}$ was confirmed by regression analyses as a significant predictor of ascending diameter $(P<.001$ in all models, with $\mathrm{R}^{2}$ ranging from 0.56 to 0.73 ; Table E1).

\section{Follow-up of Subjects With Bicuspid Aortic Valve}

Concurrent baseline echocardiographic and MRImeasured diameters at the tubular ascending tract were 
TABLE 1. Baseline features and aortic diameters

\begin{tabular}{|c|c|c|c|}
\hline & $\begin{array}{c}\text { BAV } \\
(\mathbf{n}=\mathbf{3 6}) \\
\end{array}$ & $\begin{array}{c}\text { TAV } \\
(\mathbf{n}=\mathbf{1 0})\end{array}$ & $\begin{array}{c}P \\
\text { value }\end{array}$ \\
\hline Age (y) & $28 \pm 7$ & $33 \pm 12$ & .13 \\
\hline Sex (male) & $33(89 \%)$ & $9(90 \%)$ & .71 \\
\hline Body surface area $\left(\mathrm{m}^{2}\right)$ & $1.85 \pm 0.2$ & $1.93 \pm 0.2$ & .33 \\
\hline Systolic blood pressure (mm Hg) & $119 \pm 7$ & $120 \pm 9$ & .16 \\
\hline Diastolic blood pressure & $71 \pm 8$ & $74 \pm 10$ & .60 \\
\hline Peak velocity $(\mathrm{m} / \mathrm{s})$ & $1.25 \pm 0.2$ & $1.11 \pm 0.2$ & .09 \\
\hline Mild aortic regurgitation & $6(17 \%)$ & $1(10 \%)$ & .52 \\
\hline \multicolumn{4}{|l|}{ Aortic diameters* (mm) } \\
\hline Sinus $_{\text {right }}$ & $33 \pm 3$ & $32 \pm 6$ & .69 \\
\hline Sinus $_{\text {left }}$ & $33 \pm 3$ & $32 \pm 5$ & .52 \\
\hline Sinus $_{\text {non }}$ & $35 \pm 3$ & $34 \pm 4$ & .63 \\
\hline STJ $_{\text {right }}$ & $26 \pm 4$ & $27 \pm 7$ & .58 \\
\hline $\mathrm{STJ}_{\text {left }}$ & $27 \pm 5$ & $26 \pm 6$ & .34 \\
\hline $\mathrm{STJ}_{\text {non }}$ & $29 \pm 4$ & $29 \pm 4$ & .92 \\
\hline Ascending $_{\text {right }}$ & $31 \pm 5$ & $27 \pm 4$ & .06 \\
\hline Ascending left & $31 \pm 5$ & $27 \pm 4$ & .017 \\
\hline Ascending $_{\text {non }}$ & $32 \pm 5$ & $28 \pm 5$ & .026 \\
\hline Ascending $_{\text {mean }}$ & $31 \pm 5$ & $27 \pm 5$ & .026 \\
\hline Indexed ascending ${ }_{\text {mean }}\left(\mathrm{cm} / \mathrm{m}^{2}\right)$ & $1.7 \pm 0.2$ & $1.4 \pm 0.2$ & $<.001$ \\
\hline
\end{tabular}

consistent (correlations ranging from $r=0.76$ to $r=0.92$, $P<.001)$. Mean follow-up time was $3.7 \pm 2$ years, ranging from 9 months to 7 years $(n=31$; the other 5 subjects with BAV had a follow-up time period $<6$ months). BAV stenosis (moderate) developed in only 1 patient. The average growth rate was $0.76 \mathrm{~mm}$ per year (median, $0.6 \mathrm{~mm} / \mathrm{y}$; interquartile range, 0.27-1.2). COA was significantly correlated with the annual rate of aortic enlargement (the strongest correlation was found for $\mathrm{COA}_{\text {left }}$; Figure $5, B$ ) and independently predicted aortic growth velocity in linear regression models correcting for initial diameters and WS (Table E1).

\section{DISCUSSION}

The present study was undertaken to identify possible early imaging predictors of BAV-related aortopathy in patients with nonstenotic, nonregurgitant BAV. The main finding was that a quantifier of the restricted motion of the BAV conjoint cusp, the COA, independently predicted the aortic growth rate in the follow-up, thus showing potential clinical relevance as a risk stratification tool.

To date, we have addressed only the most common morphotype (right-left coronary cusp fusion). The second most frequent anatomy, right noncoronary fusion, has been linked to arch involvement, ${ }^{5,7,17,18}$ whereas this study focused on the mid-ascending tract, the level of preferential dilatation with BAV. ${ }^{1,6}$ In this phenotypically homogeneous setting, early signs of valve and vessel dysfunction were found (ie, anomalous orifice geometry, flow deflection, and heterogeneous aortic WS). The finding of eccentric valve opening and consequent flow derangement, even in the echocardiographically normofunctional BAV, was not surprising ${ }^{3}$; however, the originality of the present findings is in the documentation of the feasibility and reproducibility of the quantification of cusp-opening restriction for a potential clinical use.

\section{Quantifying the Abnormality of the "Normal" Bicuspid Aortic Valve}

Misshaped BAV orifice was quantified by measuring the opening angle of the conjoint cusp in longitudinal views of the aorta. Average normal COAs were $75^{\circ}$ to $77^{\circ}$, whereas fused leaflet COAs (averaging $63^{\circ}$ ) indicated restricted leaflet motility, with systolic misalignment to the outflow axis. This may be caused, as suggested by the significant correlation with $\mathrm{ICD}_{\text {non }}$, by the peculiar geometry of the BAV. ${ }^{19}$ The fused leaflets together can cover an area ranging, according to the individual degree of dysmorphism, from the normal two thirds to half of the total valve

TABLE 2. Intragroup and intergroup comparisons of measurements

\begin{tabular}{|c|c|c|c|c|c|}
\hline & $\operatorname{BAV}(n=36)$ & $\begin{array}{c}\text { Within BAV } \\
P \text { value* }\end{array}$ & TAV $(\mathbf{n}=\mathbf{1 0})$ & $\begin{array}{c}\text { Within TAV } \\
P \text { value* }\end{array}$ & $\begin{array}{c}\text { BAV vs TAV } \\
P \text { value } \\
\end{array}$ \\
\hline $\operatorname{ICD}_{\text {right }}(\mathrm{mm})$ & $22 \pm 3$ & $<.001$ & $24 \pm 4$ & .17 & .11 \\
\hline $\mathrm{ICD}_{\text {left }}$ & $20 \pm 3$ & & $21 \pm 3$ & & .30 \\
\hline $\mathrm{ICD}_{\text {non }}$ & $26 \pm 3$ & & $22 \pm 4$ & & $<.001$ \\
\hline Sinus height right $^{\dagger}(\mathrm{mm})$ & $20 \pm 3$ & $<.001$ & $22 \pm 4$ & .84 & .19 \\
\hline Sinus height $\mathrm{left}_{\mathrm{l}}$ & $20 \pm 2$ & & $21 \pm 4$ & & .58 \\
\hline Sinus height $_{\text {non }}$ & $23 \pm 2$ & & $22 \pm 3$ & & .21 \\
\hline $\mathrm{COA}_{\text {right }}\left({ }^{\circ}\right)$ & $64 \pm 5$ & $<.001$ & $77 \pm 4$ & .38 & $<.001$ \\
\hline $\mathrm{COA}_{\text {left }}$ & $62 \pm 5$ & & $77 \pm 4$ & & $<.001$ \\
\hline $\mathrm{COA}_{\text {non }}$ & $76 \pm 3$ & & $75 \pm 3$ & & .41 \\
\hline $\mathrm{WS}_{\text {right }}(\%)$ & $10.4 \pm 4.2$ & .005 & $10.9 \pm 1.9$ & .90 & .89 \\
\hline $\mathrm{WS}_{\text {left }}$ & $9.9 \pm 5.1$ & & $10.7 \pm 1.7$ & & .64 \\
\hline $\mathrm{WS}_{\text {non }}$ & $7.4 \pm 2.5$ & & $10.6 \pm 1.7$ & & $<.001$ \\
\hline
\end{tabular}

$B A V$, Bicuspid aortic valve; $T A V$, tricuspid aortic valve; $I C D$, intercommissural distance; $C O A$, cusp opening angle; $W S$, wall strain. ${ }^{P} P$ values by analysis of variance test (multiple comparisons between scan-planes). $\dagger$ Sinus height $=$ distance between the annular plane and the sinotubular junction level. 

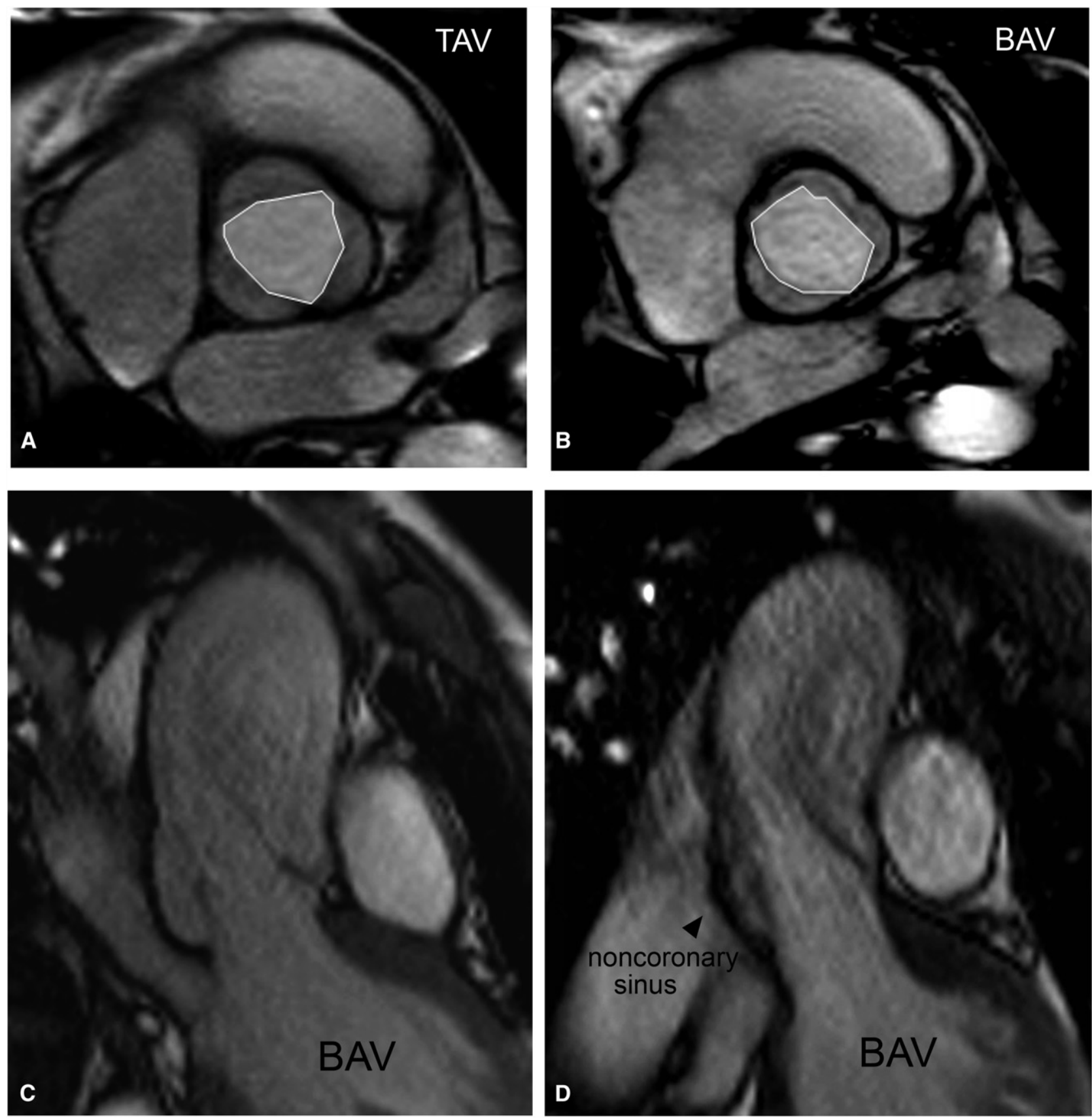

FIGURE 3. Compared with TAV, the nonstenotic BAV showed a misshaped orifice in systole, although planimetric orifice areas and peak velocities were not significantly different (A, B). Long-axis "noncoronary" views (peak systolic frames from true-FISP cine-sequences) showed a skewed jet stream, directed toward the right-lateral wall of the ascending tract $(\mathrm{C}$ and $\mathrm{D}$, left $) . B A V$, Bicuspid aortic valve; $T A V$, tricuspid aortic valve.

surface. Thus, wider $\mathrm{ICD}_{\text {non }}$ corresponds to more underdeveloped fused leaflets, with more restricted excursions. The inverse correlation with age may confirm the hypothesis ${ }^{3,15}$ that long-standing overstress prompts cusp sclerosis, increasing its stiffness over time, thus progressively restricting motility. Other anatomic factors, in addition to commissural orientation and stiffness, may influence cusp opening, including, for example, the height of attachment of the vestigial commissure at the aortic wall and the presence and thickness of the raphe.

Decreased COA represents a sign of subclinical valve dysfunction. ${ }^{3,15}$ Valve orifice, although not significantly reduced, is geometrically altered in BAV, and consequently the flow jet, albeit not enough accelerated to fulfill the definition of stenosis, is intrinsically abnormal in its direction (Figure 3). Others have observed that 

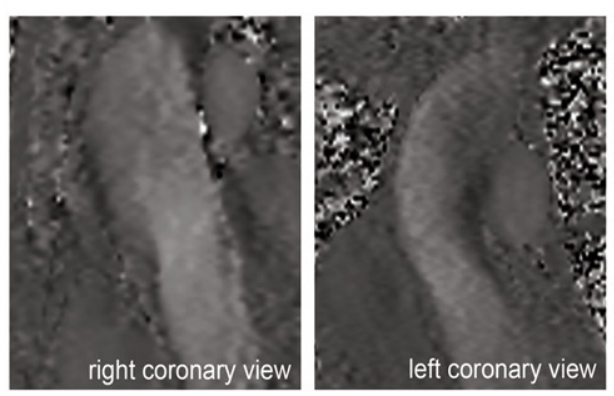

A

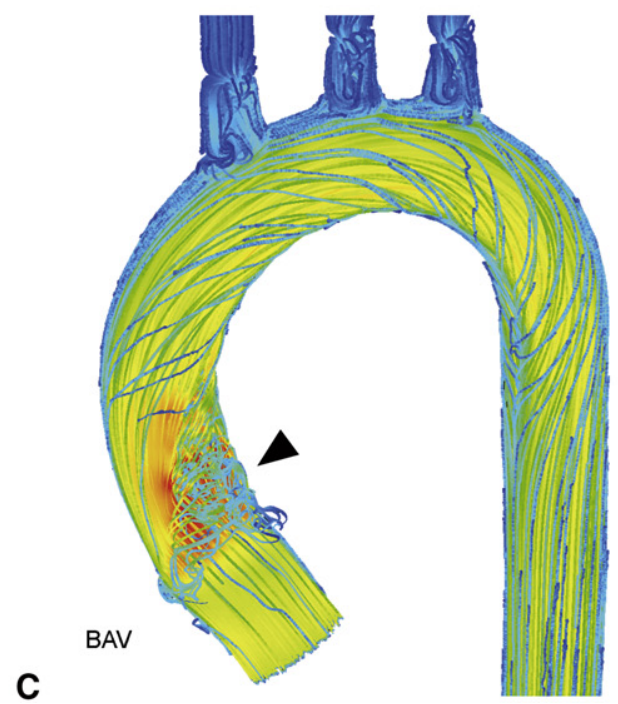

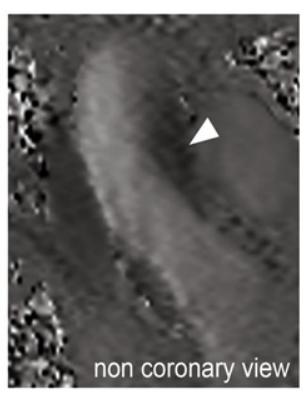

non coronary view

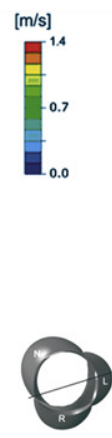

B
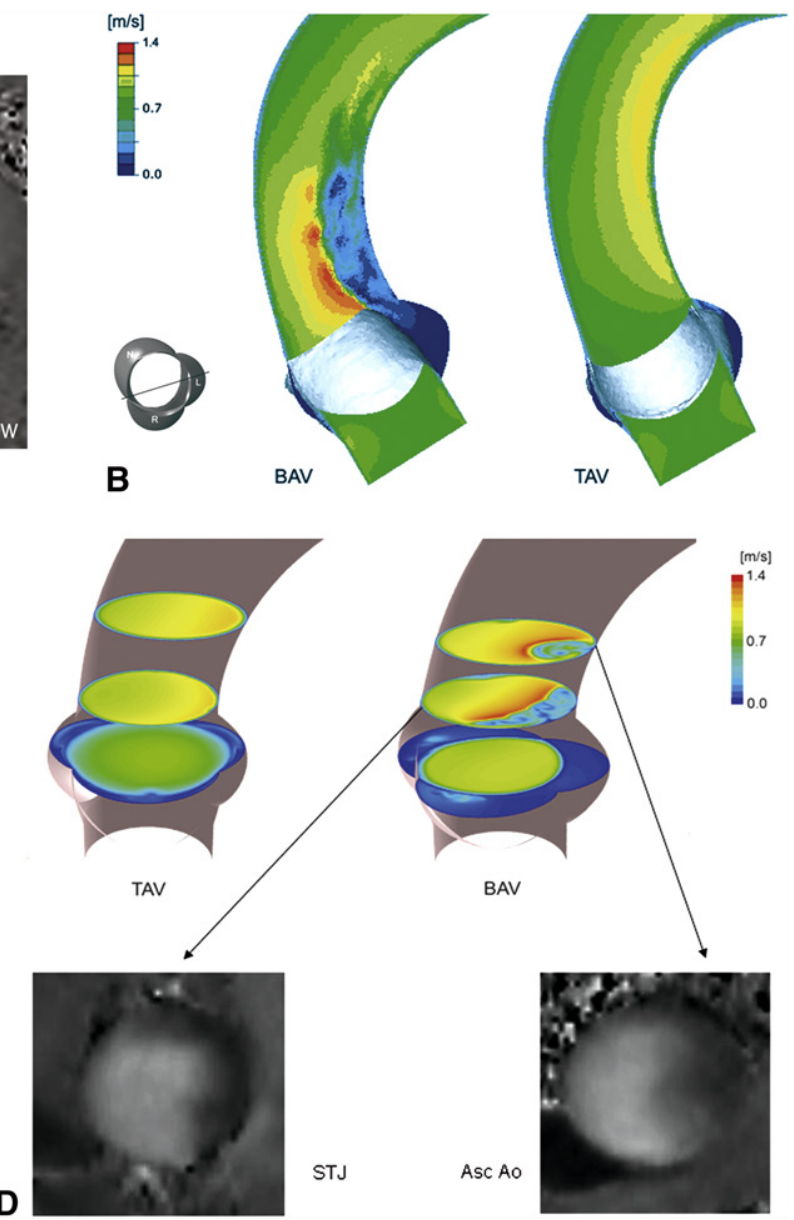

FIGURE 4. A, Phase-contrast MRI sequences with in-plane velocity encoding. The noncoronary scan-plane profiled the jet direction toward the right anterolateral wall. The dark area (white arrowhead) indicates systolic retrograde flow. B, Peak systolic flow velocity comparison between BAV and TAV computational models showing markedly less homogeneous velocities in the BAV aorta. C, Streamlines evidencing a vertical vortex above the conjoint cusp (black arrowhead). $\mathrm{D}$, Computed flow velocity patterns in cross-sections of the models were qualitatively consistent with phase-contrast images (through-plane velocity encoding) from the same levels (STJ and ascending tract). BAV, Bicuspid aortic valve; TAV, tricuspid aortic valve; STJ, sinotubular junction; Asc Ao, ascending aorta.

functional severity of aortic stenosis increases, for a given orifice area, with increasing eccentricity. ${ }^{20}$ The present investigation extended this concept to the nonstenotic BAV, consistent with a recent qualitative 4-dimensional flow MRI study ${ }^{18}$ showing abnormal helical aortic flow in $75 \%$ of subjects with BAV with or without stenosis or aneurysm, although the study did not quantitatively investigate the valvular mechanisms underlying flow derangement. Another recent MRI study ${ }^{21}$ found that shear stress varied significantly along the circumference of the BAV aorta. Yet, some patients had significant stenosis, possibly biasing the analysis of flow patterns; moreover, whether the observed flow disturbance was influenced by increased aortic diameters was not ruled out by the authors.

\section{Relevance to the Pathogenesis of Bicuspid Aortic Valve Aortopathy}

The significant correlations of COA with ascending diameter and aortic growth rate, confirmed by multivariable analysis, may support the hypothesis that misdirected flow is causally involved in aortopathy development in patients with right-left type of BAV. Computational models confirmed that restricted conjoint-cusp motion would be sufficient to produce this flow deflection even without increased diameters or altered wall properties. The skewed jet was directed downstream of the noncoronary sinus, toward the right-anterior aortic wall, which is the area usually referred to as the "convexity," where the typical BAV-related asymmetric dilatation preferentially develops., 52 Furthermore, the present study added to the already reported finding of reduced strain of the BAV aortic wall, ${ }^{12}$ the evidence of spatial heterogeneity of WS. Strain $^{12,13}$ is the rate of systolic distension, which is a function of distensibility (a mechanical property of the wall) and pulse pressure. Because our aim was to compare strain among 3 different radial directions in a given cross-section (the ascending tract level) of the vessel, distensibility was not calculated, because pulse 

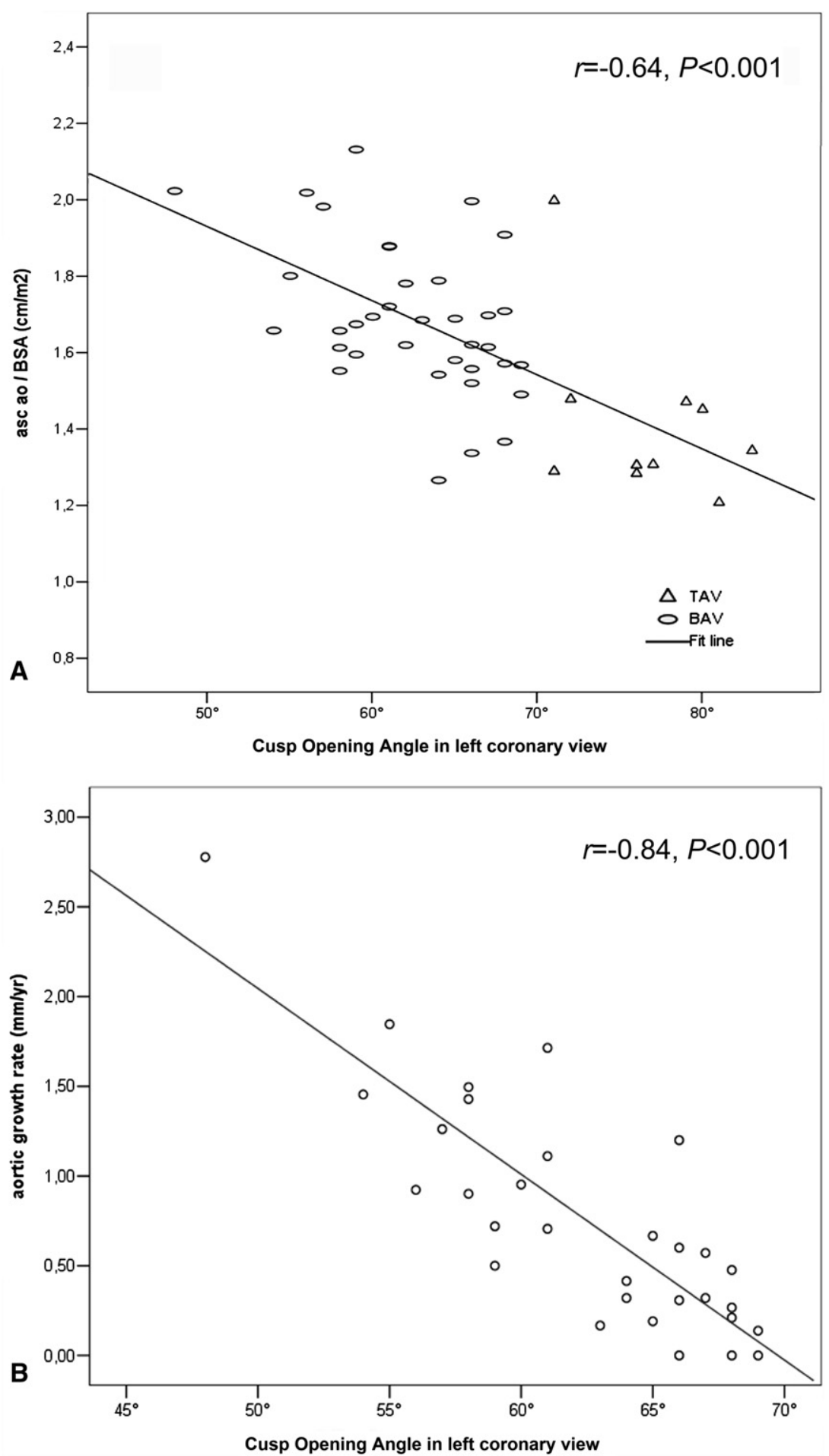

FIGURE 5. Scatter-plots showing $\mathrm{COA}_{\text {left }}$ correlation with ascending aorta diameter indexed to body surface area (A) and with growth rate of the BAV aorta at the tubular tract level (B). $B A V$, Bicuspid aortic valve; $B S A$, body surface area; $T A V$, tricuspid aortic valve.

pressure could be considered uniform. Therefore, lower strain in the direction explored by the noncoronary view than in the other directions suggested focally reduced wall distensibility, consistent with initial local alterations of collagen and elastin content. ${ }^{12}$ We previously reported that even in the normally sized or mildly dilated BAV aorta, the convexity can display initial signs of extracellular matrix degradation. ${ }^{22}$ 
According to the described mechanisms of flow-induced vascular remodeling, ${ }^{23}$ the flow jet impacting on the convexity area since birth could trigger focal aberrant expression of wall remodeling effectors. Through these mechanisms, in theory, the typical asymmetric dilatation phenotype may develop in subjects with right-left type of BAV having no congenital aortic wall fragility or a genetic defect with low expressivity. In recent experimental studies, the expression of matrix metalloprotease-2, a species of protease typically increased in BAV-related aortic dilatations ${ }^{24}$ was found to be regulated, at the gene level, by the amount of wall tension: ${ }^{25}$ Although not assessed in the present study, locally increased aortic wall tension is expected where the skewed jet from the BAV impinges on the aortic wall.

However, whether flow-induced remodeling processes are enough to trigger BAV-related aortic dilatation remains an open question that is beyond the aims of the present study. Only in the asymmetric dilatation phenotype can a fundamental causal role of altered hemodynamics be soundly argued, whereas the less frequent symmetric dilatation forms, frequently extending from the root through the arch, ${ }^{2,8,17}$ may be subtended by a greater expressivity of some coexisting genetic defect. Thus, an important challenge is to discover the clinical factors that may help to distinguish between the more and the less "malignant" forms of BAV aortopathy, to modify medical and surgical approaches accordingly.

\section{Clinical Perspectives}

The COA parameter was not derived from calculations ${ }^{21}$ or obtained by sophisticated MRI equipment, ${ }^{18}$ but was a direct absolute measurement that is potentially reproducible in any cardiac MRI laboratory and introducible in clinical practice.

Although confirmation in larger cohorts is needed, the present results suggest that COA may serve as a stratification tool to discriminate within the clinical heterogeneity of BAV phenotypes. For example, an ascending dilatation with a diameter markedly greater than predicted by the COA equation may suggest consideration of a more aggressive therapeutic approach, portending a degree of disease severity out of proportion to the hemodynamic disturbances. Moreover, regardless of diameters, an overly reduced COA, a predictor of faster growth of the ascending aorta, could mandate closer clinical surveillance. Imaging parameters (eg, COA) combined with aortopathy humoral biomarkers that may be introduced in the near future ${ }^{26}$ may help basing surgical judgment not only on dimensional criteria.

\section{Study Limitations}

A limitation was the relatively small number of patients enrolled. When designing the present study, sample homogeneity was privileged over sample size. However, the consistency of results within the BAV group and the significance of differences versus TAV were remarkable, even with this relatively small sample size. The hypotheses generated should be further verified, possibly including patients with degrees of aortic enlargement. The relation between hemodynamic factors (deflected flow) and aortic growth rate could change or even disappear as the dilatation progresses. Furthermore, a future expansion of the present research should include subjects with BAV with right noncoronary fusion and other rarer morphotypes. However, in the rare forms with 2 equally sized leaflets with no congenital fusion and just 2 sinuses, our MRI protocol cannot be applied "as is." Likewise, more female subjects with BAV should be studied, because the predominance of male gender in the present study was slightly higher than commonly reported. ${ }^{7-9}$ Finally, the exclusion of 5 patients with short follow-up from the analysis of COA correlation with aortic growth rate, to avoid possible overestimation of their rates due to annualization, must be acknowledged; however, when the 5 subjects were included in the analysis (data not shown), the correlation remained significant.

\section{CONCLUSIONS}

The COA, a quantifier of the geometrically abnormal opening of the BAV with right-left coronary leaflet fusion, proved to be an independent predictor of ascending aorta diameter and growth rate. The potential value of COA as a prognostic factor to be considered in the process of therapeutic decision deserves further verification.

The authors thank Giovanni Rossi, MD, Giovanni Dialetto, MD, Giancarlo Scognamiglio, MD, and Franco Covino, MD, cardiac imaging experts at the Monaldi Hospital, Naples, Italy, for collaboration in data acquisition.

\section{References}

1. Braverman AC. Aortic involvement in patients with a bicuspid aortic valve. Heart. 2011;97:506-13

2. Wald O, Korach A, Shapira OM. Should aortas in patients with bicuspid aortic valve really be resected at an earlier stage than tricuspid? PRO. Cardiol Clin. 2010;28:289-98.

3. Robicsek F, Thubrikar MJ, Cook JW, Fowler B. The congenitally bicuspid aortic valve: how does it function? Why does it fail? Ann Thorac Surg. 2004;77:177-85.

4. Sundt TM III. Replacement of the ascending aorta in bicuspid aortic valve disease: where do we draw the line? J Thorac Cardiovasc Surg. 2010;140:41-4.

5. Girdauskas E, Borger MA, Secknus MA, Girdauskas G, Kuntze T. Is aortopathy in bicuspid aortic valve disease a congenital defect or a result of abnormal hemodynamics? A critical reappraisal of a one-sided argument. Eur J Cardiothorac Surg. 2011;39:809-14.

6. Della Corte A, Bancone C, Quarto C, Dialetto G, Covino FE, Scardone M, et al. Predictors of ascending aortic dilatation with bicuspid aortic valve: a wide spectrum of disease expression. Eur J Cardiothorac Surg. 2007;31:397-404.

7. Schaefer BM, Lewin MB, Stout KK, Gill E, Prueitt A, Byers PH, et al. The bicuspid aortic valve: an integrated phenotypic classification of leaflet morphology and aortic root shape. Heart. 2008;94:1634-8.

8. Park CB, Greason KL, Suri RM, Michelena HI, Schaff HV, Sundt TM 3rd. Fate of nonreplaced sinuses of Valsalva in bicuspid aortic valve disease. J Thorac Cardiovasc Surg. 2011;142:278-84. 
9. Michelena HI, Desjardins VA, Avierinos JF, Russo A, Nkomo VT, Sundt TM, et al. Natural history of asymptomatic patients with normally functioning or minimally dysfunctional bicuspid aortic valve in the community. Circulation. 2008; 117:2776-84.

10. Sievers HH, Sievers HL. Aortopathy in bicuspid aortic valve disease-genes or hemodynamics? or Scylla and Charybdis? Eur J Cardiothorac Surg. 2011;39: 803-4.

11. Roman MJ, Devereux RB, Kramer-Fox R, O'Loughlin J. Two-dimensional echocardiographic aortic root dimensions in normal children and adults. Am J Cardiol. 1989;64:507-12.

12. Nistri S, Grande-Allen J, Noale M, Basso C, Siviero P, Maggi S, et al. Aortic elasticity and size in bicuspid aortic valve syndrome. Eur Heart J. 2008;29: 472-9.

13. Yap SC, Nemes A, Meijboom FJ, Galema TW, Geleijnse ML, ten Cate FJ, et al. Abnormal aortic elastic properties in adults with congenital valvular aortic stenosis. Int J Cardiol. 2008;128:336-41.

14. Conti CA, Votta E, Della Corte A, Del Viscovo L, Bancone C, Cotrufo M, et al. Dynamic finite element analysis of the aortic root from MRI-derived parameters. Med Eng Phys. 2010;32:212-21.

15. Conti CA, Della Corte A, Votta E, Del Viscovo L, Bancone C, De Santo LS, et al. Biomechanical implications of the congenital bicuspid aortic valve: a finite element study of aortic root function from in vivo data. $J$ Thorac Cardiovasc Surg. 2010;140:890-6.

16. Del Gaudio C, Morbiducci U, Grigioni M. Time dependent non-Newtonian numerical study of the flow field in a realistic model of aortic arch. Int J Artif Organs. 2006;29:709-18.

17. Della Corte A, Cotrufo M. Bicuspid aortopathy or bicuspid aortopathies? The risk in generalizing. J Thorac Cardiovasc Surg. 2008;136:1604.
18. Hope MD, Hope TA, Meadows AK, Ordovas KG, Urbania TH, Alley MT, et al Bicuspid aortic valve: four-dimensional MR evaluation of ascending aortic systolic flow patterns. Radiology. 2010;255:53-61.

19. Angelini A, Ho SY, Anderson RH, Devine WA, Zuberbuhler JR, Becker AE, et al The morphology of the normal aortic valve as compared with the aortic valve having two leaflets. J Thorac Cardiovasc Surg. 1989;98:362-7.

20. Richards KE, Deserranno D, Donal E, Greenberg NL, Thomas JD, Garcia MJ. Influence of structural geometry on the severity of bicuspid aortic stenosis. Am J Physiol Heart Circ Physiol. 2004;287:1410-6.

21. Barker AJ, Lanning C, Shandas R. Quantification of haemodynamic wall shear stress in patients with bicuspid aortic valve using phase-contrast MRI. Ann Biomed Eng. 2010;38:788-800.

22. Della Corte A, Quarto C, Bancone C, Castaldo C, Di Meglio F, Nurzynska D et al. Spatiotemporal patterns of smooth muscle cell changes in ascending aortic dilatation with bicuspid and tricuspid aortic valve stenosis: focus on cell-matrix signaling. J Thorac Cardiovasc Surg. 2008;135:8-18

23. Lehoux S, Tronc F, Tedgui A. Mechanisms of blood flow-induced vascular enlargement. Biorheology. 2002;39:319-24.

24. Ikonomidis JS, Jones JA, Barbour JR, Stroud RE, Clark LL, Kaplan BS, et al. Expression of matrix metalloproteinases and endogenous inhibitors within ascending aortic aneurysms of patients with bicuspid or tricuspid aortic valves. J Thorac Cardiovasc Surg. 2007; 133:1028-36.

25. Ruddy JM, Jones JA, Stroud RE, Mukherjee R, Spinale FG, Ikonomidis JS. Differential effect of wall tension on matrix metalloproteinase promoter activation in the thoracic aorta. J Surg Res. 2010;160:333-9.

26. Trimarchi S, Sangiorgi G, Sang X, Rampoldi V, Suzuki T, Eagle KA, et al. In search of blood tests for thoracic aortic diseases. Ann Thorac Surg. 2010;90: 1735-42. 

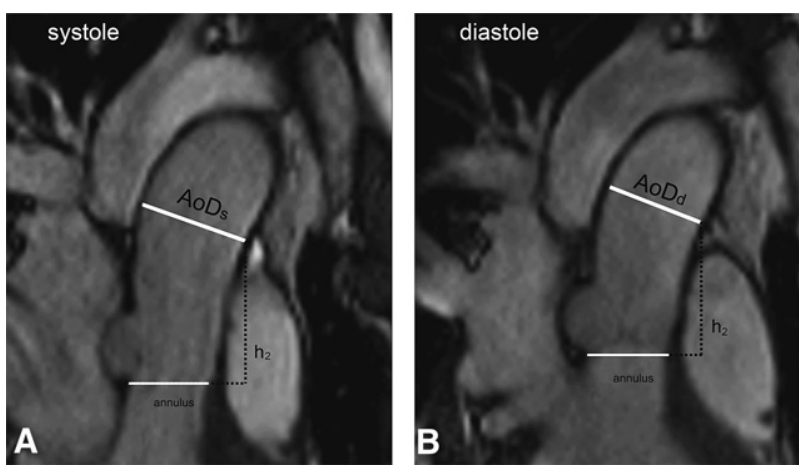

FIGURE E1. Ascending diameter measurements for WS calculation (noncoronary view) in systole (A) and diastole (B). Comparability of $h_{2}$ values ensured consistency of measurement levels among the 3 views and between BAV and TAV groups (all $P=\mathrm{NS}$ ). AoDs, Systolic diameter; $A o D d$, diastolic diameter; $h_{2}$, distance from the annular plane.

TABLE E1. Multivariable predictors in subjects with bicuspid aortic valve

\begin{tabular}{|c|c|c|c|c|c|}
\hline Outcome variable & Predictors & Coefficient & SE & $P$ value & $\mathbf{R}^{2}$ \\
\hline Ascending $g_{\text {right }}$ & $\mathrm{COA}_{\text {left }}$ & -0.75 & 0.17 & $<.001$ & 0.56 \\
\hline \multirow[t]{2}{*}{ Ascending ${ }_{\text {left }}$} & $\mathrm{COA}_{\text {left }}$ & -0.75 & 0.16 & $<.001$ & 0.73 \\
\hline & $\mathrm{WS}_{\text {non }}$ & -0.29 & 0.13 & .017 & \\
\hline \multirow[t]{3}{*}{ Ascending non $_{1}$} & $\mathrm{COA}_{\text {right }}$ & -0.75 & 0.14 & $<.001$ & 0.69 \\
\hline & $\mathrm{ICD}_{\text {non }}$ & 0.26 & 0.17 & .027 & \\
\hline & BSA & 0.49 & 2.8 & .002 & \\
\hline Ascending mean & $\mathrm{COA}_{\text {left }}$ & -0.77 & 0.15 & $<.001$ & 0.58 \\
\hline \multirow[t]{2}{*}{ Indexed ascending $g_{\text {mean }}$} & $\mathrm{COA}_{\text {right }}$ & -0.43 & 0.01 & .007 & 0.42 \\
\hline & Sinus $_{\text {left }}$ & 0.32 & 0.01 & .04 & \\
\hline Growth rate & $\mathrm{COA}_{\text {left }}$ & -0.84 & 0.01 & $<.001$ & 0.70 \\
\hline
\end{tabular}

$C O A$, Cusp opening angle; $W S$, all strain; $I C D$, intercommissural distance; $B S A$, body surface area; $S E$, standard error for the coefficient; sinus, sinus diameter. 